\title{
PDE4 inhibitors have no effect on eotaxin expression in human primary bronchial epithelial cells
}

\author{
Magdalena Paplińska-Goryca ${ }^{凶}$, Ryszarda Chazan and Hanna Grubek-Jaworska \\ Department of Internal Medicine, Pneumonology and Allergology, Medical University of Warsaw, Warsaw, Poland
}

\begin{abstract}
The bronchial epithelium is a very important factor during the inflammatory response, it produces many key regulators involved in the pathophysiology of asthma and COPD. Local influx of eosinophils, basophils, Th2 lymphocytes and macrophages is the source of many cytotoxic proteins, cytokines and other mediators of inflammation. These cells are attracted by eotaxins (eotaxin-1/CCL11, eotaxin-2/CCL24, eotaxin-3/CCL26). Inhibitors of phosphodiesterase 4 (PDE4) are new anti-inflammatory drugs which cause CAMP accumulation in the cell and inhibit numerous stages of allergic inflammation. The aim of our study was to evaluate the influence of PDE4 inhibitors: rolipram and RO-20-1724 on the expression of eotaxins in human primary bronchial epithelial cells. Cells were preincubated with PDE4 inhibitors for 1 hour and then stimulated with IL-4 or IL-13 alone or in combination with TNF-a. After 48 hours, eotaxin protein level was measured by ELISA and MRNA level by real time PCR. These cells produce CCL24 and CCL26. PDE4 inhibitors increased CCL24 and CCL26 mRNA level irrespectively of the used stimulators. Rolipram and RO-201724 had no effect on eotaxin protein production in our experimental conditions. Thus PDE4 inhibitors have no effect on eotaxin protein expression in human primary bronchial epithelial cells. In vitro experiments should be performed using a primary cell model rather than immortalized lines.
\end{abstract}

Key words: eotaxins, primary bronchial epithelial cells, PDE4 inhibitors.

Received: 26 March, 2012; revised: 27July, 2012; accepted: 24 August, 2012; available on-line: 03 September, 2012

\section{INTRODUCTION}

PDE4 (Phosphodiesterase 4) inhibitor - roflumilast, a new anti-inflammatory agent is accepted in COPD (Chronic Obstructive Pulmonary Disease) treatment (Giembycz \& Field, 2010; Rabe, 2011). Clinical trials with this group of drugs started more than a decade ago. PDE4 inhibitors increase cAMP (Cyclic Adenosine Monophosphate) accumulation in cells. cAMP as a classics second messenger regulate the level of numerous hormones, cytokines and cell-mediated response to signals from neurotransmitters. The regulation of PDE4 is of special interest in respiratory medicine because it is the main enzyme causing cAMP degradation in the structural cells of the respiratory tract and all the cells of the immunological system. PDE4 inhibitors reduce the neutrophil and eosinophil influx, inhibit pro-inflammatory mediator production, improve lung function and re- duce the number of exacerbations in obstructive pulmonary diseases (Eskandari et al., 2004; Murphy et al., 2006; Calverley et al., 2009; Buenestado et al., 2011; Rennard et al., 2011). Nowadays, an inhaled form of PDE4 inhibitor in the treatment of respiratory disorders is a hot topic. The inhaled form may reduce many side effects caused by those administered orally, and provide better exposition of the substance in the respiratory tract (Dastidar et al., 2009; Tralau-Stewart et al., 2011). PDE4 inhibitors were also shown to be beneficial in asthma treatment (Gauvreau et al., 2011).

Eotaxins (eotaxin-1/CCL11, eotaxin-2/CCL24, eotaxin-3/CCL26) are strong chemoattractants not only for eosinophils but also for basophils, macrophages, lymphocytes, and airway smooth muscle cells (Menzies-Gow et al., 2002; Dent et al., 2004; Joubert et al., 2005). Although these chemokines are produced mainly by bronchial and gut epithelial cells, other cells like eosinophils, smooth muscle cells or fibroblasts are capable of eotaxin production (Lilly et al., 1997; Badewa et al., 2002; Rokudai et al., 2006). Eotaxin expression is stimulated by Th2 cytokines: IL-4 and IL-13 (Kobayashi et al., 2004). CCL11, CCL24, CCL26, and their CCR3 receptor are important mediators of allergic and asthmatic responses. They cause the influx of eosinophils into the airways, intensify eosinophil degranulation, support eosinophilia after late asthmatic response and drive the inflammatory process (Berkman et al., 2001).

The effect of PDE4 inhibitors on eotaxin expression is still under consideration. PDE4 inhibitors were found to reduce CCL11 secretion from smooth muscle cells and human lung fibroblasts stimulated with TNF- $\alpha$ (Tumor Necrosis Factor $\alpha$ ) (Pang \& Knox, 2001; Sabatini et al., 2010). It seems that rolipram affects the eotaxin- eosinophil interaction via inhibition of cell adhesion molecule expression (Liu et al., 2004). PDE4 inhibitors reduce the eosinophil count and eotaxin concentration in BALF in animal model experiments (Silva et al., 2001; Nejman-Gryz et al., 2006), but the direct effect of PDE4 inhibition on eotaxin expression in human bronchial epithelial cells is not known.

The aim of the presented study was to evaluate the effect of PDE4 inhibitors, rolipram and RO-20-1724, on eotaxin expression in human primary bronchial epithelial cells (PBEC).

e-mail: mpaplinska@wum.edu.pl

Abbreviations: DE4, phosphodiesterase 4; COPD, Chronic Obstructive Pulmonary Disease; CAMP, Cyclic Adenosino Monophosphate; TNF-a, Tumor Necrosis Factor a; PBEC, Primary Bronchial Epithelial Cells; PKA, Protein Kinase A. 


\section{MATERIALS AND METHODS}

Cell culture. The primary bronchial epithelial cells (American Type Culture Collection, Rockville, MD, USA, ATCC-PCS-300-010) were cultured in Airway Epithelial Cell Basal Medium (ATCC cat no PCS-300-030) with the supplement Bronchial Epithelial Cell Growth Kit (ATCC cat no PCS-300-040) with $100 \mathrm{U} / \mathrm{ml}$ penicillin, $100 \mu \mathrm{g} / \mathrm{ml}$ streptomycin (PAA, Austria) at $37^{\circ} \mathrm{C}$ in $5 \% \mathrm{CO}_{2}$. The experiments were performed in the basal medium without the supplement.

Cell stimulation. When cells reached $80 \%$ confluence, they were preincubated with $10 \mathrm{mM}$ rolipram (Sigma Aldrich, Germany), RO-20-1724 (Calbiochem, Germany) for one hour. Compounds were dissolved in $96 \%$ ethanol. After that time, cells were stimulated with IL-4, IL-13 (25 ng/ml) or TNF-a $(10 \mathrm{ng} / \mathrm{ml})(\mathrm{R} \& D$ Systems, USA) for 48 hours. Cytokines were dissolved in water and a minimal amount of BSA (Bovine Serum Albumin).

Protein measurement. Culture supernatants were used to detect CCL11, CCL24 and CCL26 using ELISA kits (R\&D Systems, USA) according to the manufacturer's instructions. The sensitivity of tests was: $5 \mathrm{pg} /$ $\mathrm{ml}, 2.5 \mathrm{pg} / \mathrm{ml}$, and $2.33 \mathrm{pg} / \mathrm{ml}$ for CCL11, CCL24 and CCL26, respectively. The optical density was read at $450 \mathrm{~nm}$ with correction at $570 \mathrm{~nm}$.

RNA isolation and determination of eotaxin mRNA expression levels. Total RNA was isolated from cells using Trizol (Invitrogen, USA). The purity and concentration of isolated RNA was measured using the $260 / 280 \mathrm{~nm}$ absorbance ratio in a spectrophotometer (Beckman, USA) type DU650. One microgram of RNA was used for reverse transcription using quantitative $\mathrm{Su}-$ perScript III First-Strand Synthesis SuperMix (Invitrogen, USA). Quantitative real-time PCR evaluation was performed with an ABI-Prism 7500 Sequence Detector System (Applied Biosystems, USA). For real-time PCR, $1 \mu \mathrm{l}$ of cDNA was amplified in a $25 \mu \mathrm{l}$ PCR volume containing Power SYBR Green PCR master mix (Applied Biosystems, USA) with 150 nmoles of specific primers. Each sample was measured in duplicate. The sequences of primers were as follows: Eotaxin-1: forward, 5'CTCGCTGGGCCAGCTTCTGTC3'; reverse, 5'GGCT'T'TGGAGT'TGGAGAT'T'T'T'TGG3' (227 bp). Eotaxin-2: forward, 5'CACATCATCCCTACGGGCTCT3'; reverse, 5'GGT'TGCCAGGATATCTCTGGACAGGG3' (288 bp). Eotaxin-3: forward, 5'GGAACTGCCACACGTGGGAGTGAC3'; reverse, 5'CTCTGGGAGGAAACACCCTCTCC3' (354 bp) GAPDH: forward, 5'-GAAGGTGAAGGTCGGAGTC-3'; reverse, 5'-GAAGATGGTGATGGGATTTC-3' (226 bp).

For cDNA amplification, a 10-minute incubation at $95^{\circ} \mathrm{C}$ was performed to activate AmpliTaqGold DNA Polymerase followed by 45 cycles, each of $15 \mathrm{~s}$ and at $95^{\circ} \mathrm{C}$ and $1 \mathrm{~min}$ at $60^{\circ} \mathrm{C}$. Glyceraldehyde-3-phosphate dehydrogenase (GAPDH) was used as an internal control in order to normalize CCL11, CCL24, and CCL26 expression levels. The results were expressed as Relative Quantification units (fold change).

Relative quantification values were calculated by the $2 \Delta \Delta C T$ method. The cycle thresholds (CT) for the target amplicon and for the endogenous control (GAPDH) were determined for each sample. Differences were calculated between these two CTs and called $\triangle \mathrm{CT}$, in order to account for the differences in the amount of total nucleic acid taken for each reaction. The value of $\Delta C T$ for unstimulated cells (calibrator) was subtracted from the $\Delta C T$ of each sample and termed $\Delta \Delta C T$. The value of the target normalized to the endogenous control for experimental samples relative to that in the calibrator, was then calculated by the formula $2 \Delta \Delta \mathrm{CT}$.

Statistical analysis. Data were analyzed using the Mann-Whitney U-test. $P$-value $<0.05$ was considered statistically significant.
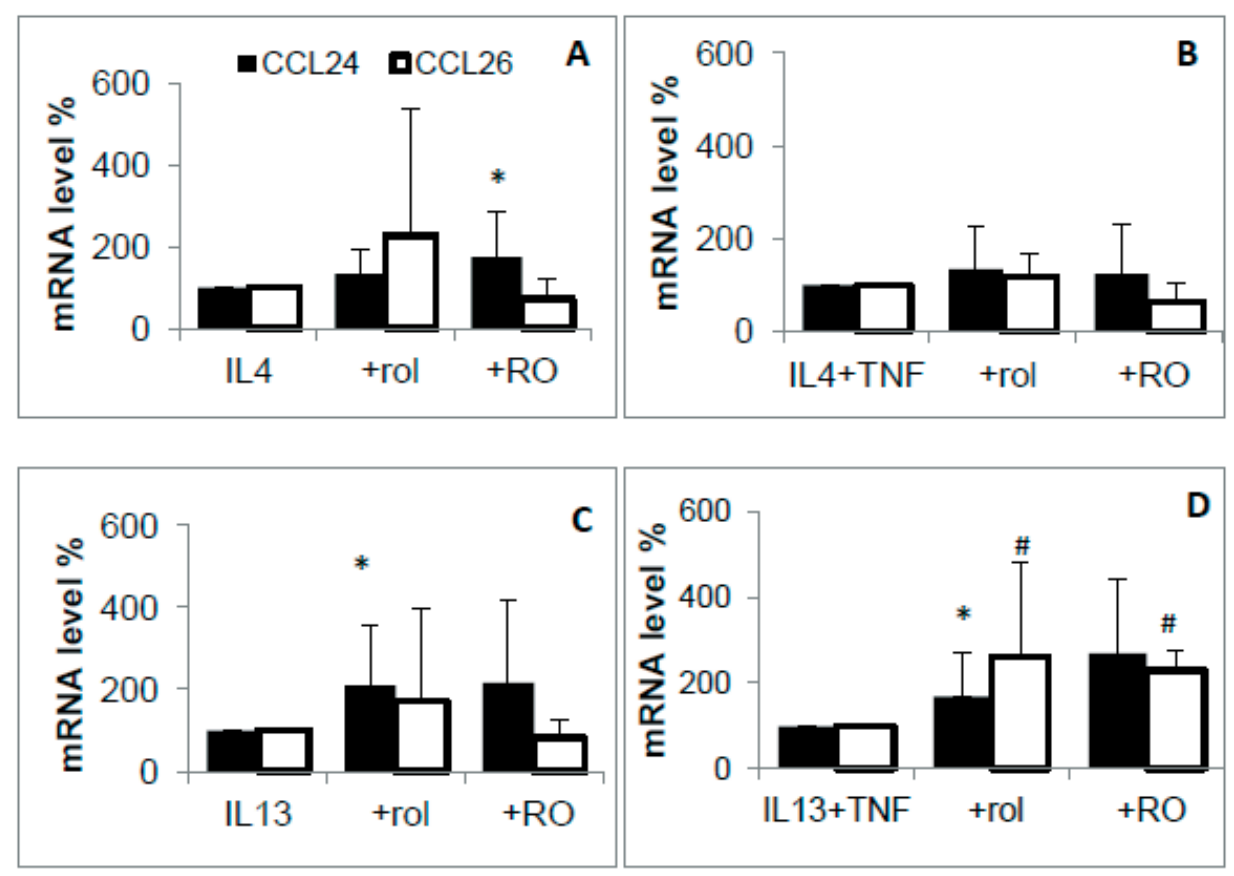

Figure 1. Effect of PDE4 inhibitors on CCL24 (black columns) and CCL26 (open columns) mRNA expression in human PBEC at 48h after stimulation with IL-4 (A) or IL-13 (C) or after co-stimulation with TNF-a (B, D).

Gene expression was measured by real time PCR as relative quantification. Gene expression after stimulation with cytokines alone (A, C) or cytokine + TNF-a (B, D) was considered as 100\%. The mean values and S.D. of 3-6 independent experiments are shown. Rol - rolipram (10 $\mu \mathrm{M})$; RO - Ro-20-1724 (10 $\mu \mathrm{M})$; IL-4 $(25 \mathrm{ng} / \mathrm{ml})$; IL-13 (25 ng/ml). ${ }^{*} \boldsymbol{p}<0.05$ expression of CCL24 as compared to effect of stimulation with IL-4 or IL-13 respectively $(\mathbf{A}, \mathbf{C})$ or with IL-13+ TNF-a (D). \#p<0.05 expression of CCL26 as compared to effect of stimulation with IL-13+ TNF-a (D). 


\section{RESULTS}

Effect of TNF-a, IL-4 and IL-13 on eotaxin expression in PBEC

We observed that human PBEC produce more CCL26 than CCL24. The mean level of CCL24 mRNA expression was $14 \pm 9$ after IL-4 stimulation and $7.4 \pm 6$ after IL-13 stimulation, while CCL26 mRNA level was $3252 \pm 3024$ and $1482 \pm 1252$, respectively (Fig. 1). The mean level of CCL24 protein was $278 \pm 211 \mathrm{pg} / \mathrm{ml}$ after IL-4 stimulation and $238 \pm 233 \mathrm{pg} / \mathrm{ml}$ after IL-13 stimulation, while CCL26 protein level was $3803 \pm 1734$ $\mathrm{pg} / \mathrm{ml}$ and $2787 \pm 2911 \mathrm{pg} / \mathrm{ml}$, respectively (Fig. 2). IL-4 induce expression of both eotaxins more strongly than IL-13. Co-stimulation with TNF- $\alpha$ significantly decreased CCL24 expression on mRNA and protein level in IL-4 and IL-13 stimulated cultures. The addition of TNF- $\alpha$ did not change CCL26 in cells treated with either IL-4 or IL-13 (Fig. 1, Fig. 2).

We did not detect CCL11 expression in PBEC in our experiments.

\section{Effect of PDE4 inhibitors on eotaxin expression in PBEC}

Rolipram and RO-20-1724 increased on average the CCL24 mRNA expression in cultures stimulated with Th2 cytokines alone or in cultures co-stimulated with TNF- $\alpha$ (Fig. 1). We noticed a statistically significant increase of CCL24 expression in cells treated with IL-4 + RO-20-1724, IL-13 + rolipram, IL-13 + TNF- $\alpha+$ rolipram as compared to stimulation with the appropriate cytokine alone. These effects were not confirmed at protein levels. In cultures stimulated by Th2 cytokines, both PDE4 inhibitors decreased the CCL24 concentration, in some cultures also the CCL26 level but none of these changes were statistically significant (Fig. 2A, Fig. 2C). The changes of mRNA expression were confirmed at the protein level only in some cultures co-stimulated with TNF- $\alpha$ (Fig. 1B, Fig. 1D, Fig. 2B, Fig. 2D).
Rolipram increased CCL26 expression more effectively than RO-20-1724, but only in cultures stimulated with IL-13 + TNF- $\alpha$ the augmentation of CCL26 mRNA expression was statistically significant (Fig. 1). It is difficult to determine the effect of RO-20-1724 on CCL26 expression. The only significant increase caused by RO20-1724 was observed in cells stimulated with IL-13 + TNF- $\alpha$ (Fig. 1D). PDE4 inhibitors did not affect CCL26 protein production in any of the applied combinations.

The effect of PDE4 inhibitors was similar for both eotaxins. Rolipram increased both CCL24 and CCL26 mRNA expression. The trend in changes in the protein level after PDE4 inhibitor incubation was strikingly similar in cultures stimulated with IL-13, IL-13 + TNF- $\alpha$ and very close after IL- 4 and IL- $4+\mathrm{TNF}-\alpha$ stimulation with the exception of IL-4 + RO-20-1724.

\section{DISCUSSION}

Our results indicate that PDE4 inhibitors have no major effect on the expression of eotaxins in primary bronchial epithelial cells. This effect was observed independently of the eotaxin expression stimulators used in the experiments. To our knowledge, this is the first study concerning direct effects of PDE4 inhibitors on eotaxin expression in the cultures of primary human bronchial epithelium. The presented results are in opposition to our results obtained with an immortalized cell line - BEAS-2B, where the decrease of eotaxins by PDE4 inhibitors had depended on co-stimulation with TNF- $\alpha$ (Paplinska et al., 2011).

We did not find CCL11 expression in the primary human bronchial epithelial cells, in contrast to the immortalized line BEAS-2B. This observation was confirmed by other authors (Komiya et al., 2003, Matsukura et al., 2006). They also did not detect CCL11 expression in normal human bronchial epithelial cells. Similarly to the above mentioned authors, CCL26 is the eotaxin produced in highest amounts in our study.
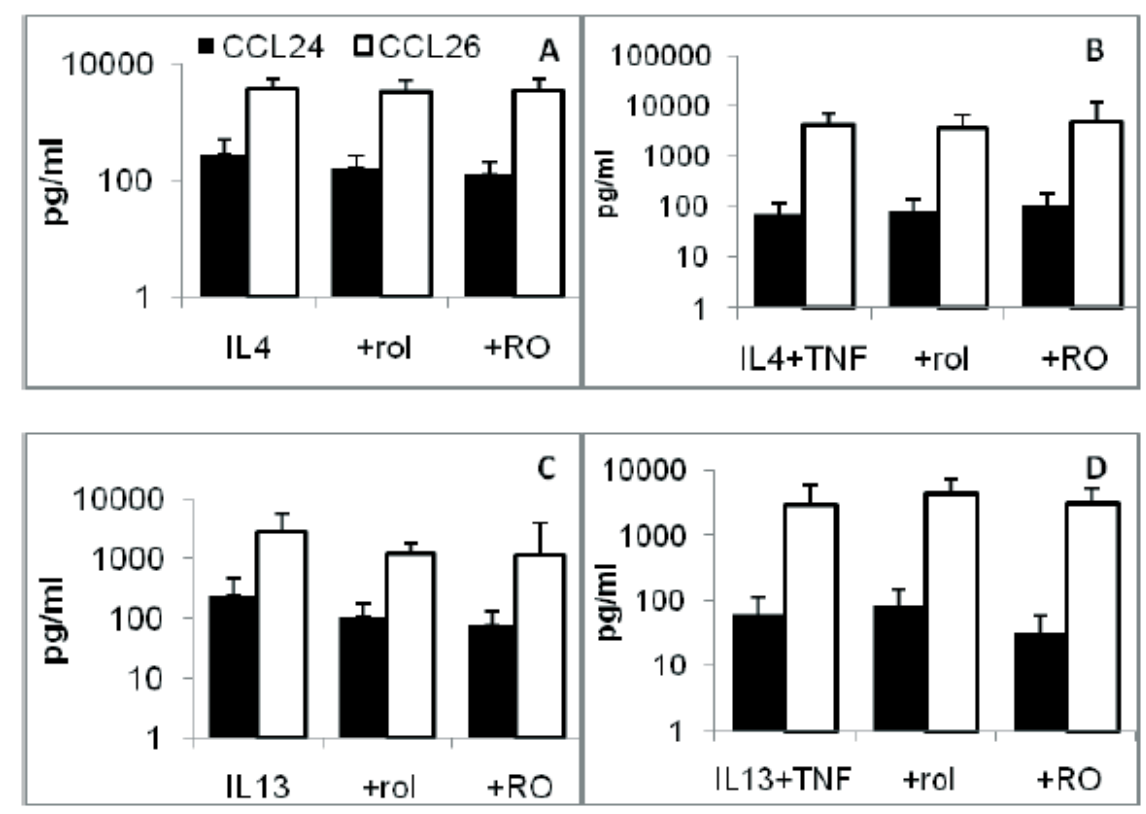

Figure 2. Effect of PDE4 inhibitors on CCL24 (black columns) and CCL26 (open columns) release by human PBEC stimulated by IL-4 (A) or IL-13 (C); and co-stimulated with TNF-a (B, D).

Eotaxin accumulation in the medium was measured by ELISA at $48 \mathrm{~h}$ after stimulation. The mean values and S.D. of 6 determinations

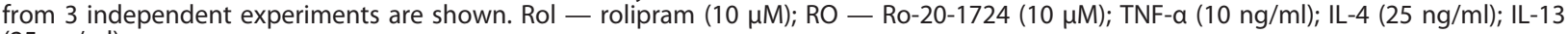
$(25 \mathrm{ng} / \mathrm{ml})$. 
The results obtained in this study concerning the effect of PDE4 inhibitors on eotaxin expression in bronchial epithelium did not confirm those previously published (Paplinska et al., 2011). We used the same stimulator doses as in the BEAS-2B experiments. TNF- $\alpha$ co-stimulation inhibited CCL24 production, and had no effect on CCL26 expression in PBEC in the presented work. This result is very surprising because TNF- $\alpha$ is known to induce eotaxin expression in the bronchial epithelial cell lines and very often, used in combination with Th2 cytokines, to up regulate eotaxin expression (Fujisawa et al., 2000; Heiman et al., 2005). Komiya et al. also noticed an inhibitory effect of TNF- $\alpha$ on CCL24 and CCL26 expression in cultures co-stimulated with IL-4 in primary bronchial epithelium (Komiya et al., 2003).

The effect of PDE4 inhibitors on eotaxin expression in the PBEC is ambiguous. In some cases, we observed a discrepancy between mRNA and a protein levels. The protein level of CCL24 and CCL26 seems to be unchanged, or decreased by PDE4 inhibitors, in contrast to mRNA levels. The disproportions between mRNA and protein levels are biologically possible. Firstly, because of many posttranscriptial processes not all of mRNA is translated to proteins in cells. Secondly, mRNA and proteins may differ substantially in their in vivo half-lives. The level of mRNA measured after the stimulation does not have to reflect the protein concentration in the cell, because mRNA can already be degraded and the protein is still present. Many authors show the lack of correlations between mRNA and protein levels (Chen et al., 2002; Greenbaum et al., 2003; Li \& Xie, 2011). It has been estimated that only one third of expressed mRNA correlates with the protein and it concerns the high expressed mRNA (Gry et al., 2009). It also cannot be excluded that the changes in mRNA expression were too weak to be seen on the protein level.

It has been documented that cAMP increase (caused by a PDE4 inhibitor, or forskolin — the direct activator of adenylyl cyclase, or 8Br-cAMP - the cAMP analog), reduces the CCL11 level in BEAS-2B, human lung fibroblasts, or in human airway smooth muscle cells (Wuyts et al., 2003; Chu et al., 2010; Sabatini et al., 2010). We previously showed that PDE4 inhibitors decrease CCL11 and CCL26 expression in BEAS-2B but only in cultures stimulated with Th2 cytokines and TNF- $\alpha$ simultaneously. It cannot be excluded that eotaxin decrease is not caused directly by cAMP elevation. The reaction may be partly PKA (Protein Kinase A) dependent. The activity of PKA is controlled directly by cAMP. PKA seems to reduce the activity of the main kinases which take part in the eotaxin expression pathway. Other authors claim that rolipram inhibits $\mathrm{NF} x \mathrm{~B}$ (Nuclear Factor $x \mathrm{~B}$ ) (Hervé et al., 2008). Our study performed on human primary bronchial epithelial cells gave results which are in contrast with the above mentioned publications but none of those experiments were made using primary cells.

The reason for the differences between the immortalized and primary cells is due to the cell line biology. Both lines come from the same level of the respiratory tract. Some differences between normal and immortalized cell lines have been observed (Stewart et al., 2012). BEAS-2B were obtained from primary human lung epithelial cells by transformation with 12 /SV40 adenovirus for the immortalization. These cells retain the characteristics of lung epithelial cells, such as the presence of keratin, the ability of cubic differentiation, the capacity for mucus production after inoculation on a collagen medium (Reddel et al., 1988). However, this cell line has changed some regulatory genes. BEAS-2B and the pri- mary cell line differ partly in the response to rhinovirus (RV) infection. Both cell lines secrete IL- 6 and IL- 8 after RV infection, but only the primary cells also produce IL-1 $\beta$ and TNF- $\alpha$ (Griego et al., 2000; Suzuki et al., $2000)$. Both cell lines differ in the expression of some antigen presenting molecules: BEAS-2B cells have less CD80 and CD86 on their surface than primary respiratory epithelial cells (Oei et al., 2004). Kim et al. (2005) demonstrated the absence of B7-DC expression (surface co-stimulatory molecule, ligand $\mathrm{T}$ lymphocyte) in freshly isolated primary nasal epithelial cells, and constitutive expression of this gene in BEAS-2B cells (Kim et al., 2005). The authors suggest that BEAS-2B cells have acquired a fixed expression of B7 homologs as a result of the process of the immortalization. Differences in the expression of many genes involved in the cell cycle and apoptosis between these two cell lines have been shown (Shen et al., 2006). Changes are related to carcinogenesis and may reflect processes that occur in the early stages of cancer, when the cells acquire the ability to avoid the ageing process despite of multiple divisions. In the context of these observations, it seems that primary cell lines more reliably reflect the complex processes occurring in vivo, and the primary cell lines obtained from patients should be used in the studies concerning the role of the airway epithelial cells in inflammatory lung disease.

\section{REFERENCES}

Badewa AP, Hudson CE, Heiman AS (2002) Regulatory effects of eotaxin eotaxin- 2 and eotaxin-3 on eosinophil degranulation and superoxide anion generation. Exp Biol Med (Maywood) 227: 645-651.

Berkman N, Ohnona S, Chung FK, Breuer R (2001) Eotaxin-3 but not eotaxin gene expression is upregulated in asthmatics 24 hours after allergen challenge. Am J Respir Cell Mol Biol 24: 682-687.

Buenestado A, Grassin-Delyle S, Naline E, Faisy C, Israël-Biet D, Sage E, Bellamy JF, Tenor H, Devillier P (2011) Roflumilast inhibits the release of chemokines and TNF- $\alpha$ from human lung macrophages stimulated with lipopolysaccharide. Br J Pharmacol.

Calverley PMA, Rabe KF, Goehring U-M, Kristiansen S, Fabbri LM, and Martinez FJ (2009) Roflumilast in symptomatic chronic obstructive pulmonary disease: two randomised clinical trials. Lancet 374: 685-694.

Chen G, Gharib TG, Huang C-C, Taylor JMG, Misek DE, Kardia SLR, Giordano TJ, Iannettoni MD, Orringer MB, Hanash SM et al. (2002) Discordant protein and mRNA expression in lung adenocarcinomas. Mol Cell Proteomics 1: 304-313.

Chu Y-T, Chang T-T, Jong Y-J, Kuo P-L, Lee H-M, Lee M-S, Chang H-W, Hung C-H (2010) Suppressive effects of formoterol and salmeterol on eotaxin-1 in bronchial epithelial cells. Pediatr Allergy Immunol 21: 345-352.

Dastidar SG, Ray A, Shirumalla R, Rajagopal D, Chaudhary S, Nanda K, Sharma P, Seth MK, Balachandran S, Gupta N et al (2009) Pharmacology of a novel orally active PDE4 inhibitor. Pharmacology 83: 275-286.

Dent G, Hadjicharalambous C, Yoshikawa T, Handy RLC, Powell J, Anderson IK, Louis R, Davies DE, Djukanovic R (2004) Contribution of eotaxin-1 to eosinophil chemotactic activity of moderate and severe asthmatic sputum. Am I Respir Crit Care Med 169: 1110-1117.

Eskandari N, Wickramasinghe T, Peachell PT (2004) Effects of phosphodiesterase inhibitors on interleukin-4 and interleukin-13 generation from human basophils. Br J Pharmacol 142: 1265-1272.

Fujisawa T, Kato Y, Atsuta J, Terada A, Iguchi K, Kamiva H, Yamada H, Nakajima T, Miyamasu M, Hirai K (2000) Chemokine production by the BEAS-2B human bronchial epithelial cells: differential regulation of eotaxin IL-8 and RANTES by TH2- and TH1-derived cytokines. I Allergy Clin Immunol 105: 126-133.

Gauvreau GM, Boulet L-P, Schmid-Wirlitsch C, Côté J, Duong M, Killian KJ, Milot J, Deschesnes F, Strinich T, Watson RM et al. (2011) Roflumilast attenuates allergen-induced inflammation in mild asthmatic subjects. Respir Res 12: 140.

Giembycz MA, Field SK (2010) Roflumilast: first phosphodiesterase 4 inhibitor approved for treatment of COPD. Drug Des Devel Ther 4: 147-158.

Greenbaum D, Colangelo C, Williams K, Gerstein M (2003) Comparing protein abundance and mRNA expression levels on a genomic scale. Genome Biol 4: 117. 
Griego SD, Weston CB, Adams JL, Tal-Singer R, and Dillon SB (2000) Role of p38 mitogen-activated protein kinase in rhinovirus-induced cytokine production by bronchial epithelial cells. I Immunol 165: 5211-5220.

Gry M, Rimini R, Strömberg S, Asplund A, Pontén F, Uhlén M, Nilsson P (2009) Correlations between RNA and protein expression profiles in 23 human cell lines. BMC Genomics 10: 365.

Heiman AS, Abonyo BO, Darling-Reed SF, Alexander MS (2005) Cytokine-stimulated human lung alveolar epithelial cells release eotaxin-2 (CCL24) and eotaxin-3 (CCL26). J Interferon Cytokine Res 25: 82-91.

Hervé R, Schmitz T, Evain-Brion D, Cabrol D, Leroy M-J, Méhats C (2008) The PDE4 inhibitor rolipram prevents NF-kappaB binding activity and proinflammatory cytokine release in human chorionic cells. J Immunol 181: 2196-2202.

Joubert P, Lajoie-Kadoch S, Labonté I, Gounni AS, Maghni K, Wellemans V, Chakir J, Laviolette M, Hamid Q, Lamkhioued B (2005) CCR3 expression and function in asthmatic airway smooth muscle cells. J Immunol 175: 2702-2708.

Kim J, Myers AC, Chen L, Pardoll DM, Truong-Tran Q-A, Lane AP, McDyer JF, Fortuno L, Schleimer RP (2005) Constitutive and inducible expression of $\mathrm{b} 7$ family of ligands by human airway epithelial cells. Am J Respir Cell Mol Biol 33: 280-289.

Kobayashi I, Yamamoto S, Nishi N, Tsuji K, Imayoshi M, Inada S, Ichiamaru T, Hamasaki Y (2004) Regulatory mechanisms of Th2 cytokine-induced eotaxin-3 production in bronchial epithelial cells: possible role of interleukin 4 receptor and nuclear factor-kappaB. Ann Allergy Asthma Immunol 93: 390-397.

Komiya A, Nagase H, Yamada H, Sekiya T, Yamaguchi M, Sano Y, Hanai N, Furuya A, Ohta K, Matsushima K et al. (2003) Concerted expression of eotaxin-1 eotaxin-2 and eotaxin- 3 in human bronchial epithelial cells. Cell Immunol 225: 91-100.

Li G-W, Xie XS (2011) Central dogma at the single-molecule level in living cells. Nature 475: 308-315.

Lilly CM, Nakamura H, Kesselman H, Nagler-Anderson C, Asano K, Garcia-Zepeda EA, Rothenberg ME, Drazen JM, Luster AD (1997) Expression of eotaxin by human lung epithelial cells: induction by cytokines and inhibition by glucocorticoids. J Clin Invest 99: 17671773.

Liu J, Muñoz NM, Meliton AY, Zhu X, Lambertino AT, Xu C, Myo S, Myou S, Boetticher E, Johnson M et al (2004) Beta2-integrin adhesion caused by eotaxin but not IL-5 is blocked by PDE-4 inhibition and beta2-adrenoceptor activation in human eosinophils. Pulm Pharmacol Ther 17: 73-79.

Matsukura S, Kokubu F, Kurokawa M, Kawaguchi M, Ieki K, Kuga H, Odaka M, Suzuki S, Watanabe S, Takeuchi H et al. (2006) Synthetic double-stranded RNA induces multiple genes related to inflammation through Toll-like receptor 3 depending on NF-kappaB and/ or IRF-3 in airway epithelial cells. Clin Exp Allergy 36: 1049-1062.

Menzies-Gow A, Ying S, Sabroe I, Stubbs VL, Soler D, Williams TJ, Kay AB (2002) Eotaxin (CCL11) and eotaxin-2 (CCL24) induce recruitment of eosinophils basophils neutrophils and macrophages as well as features of early- and late-phase allergic reactions following cutaneous injection in human atopic and nonatopic volunteers. J Immunol 169: 2712-2718.

Murphy DM, Ward C, Forrest IA, Pritchard G, Jones D, Stovold R, Fisher AJ, Cawston TE, Lordan JL, Corris PA (2006) The phosphodiesterase type IV inhibitor cilomilast decreases pro-inflammatory cytokine production from primary bronchial epithelial cells in lung transplantation patients. J Heart Lung Transplant 25: 1436-1440.

Nejman-Gryz P, Grubek-Jaworska H, Glapiński J, Hoser G, Chazan $\mathrm{R}$ (2006) Effects of the phosphodiestrase-4 inhibitor rolipram on lung resistance and inflammatory reaction in experimental asthma. $J$ Physiol Pharmacol 57 (Suppl 4): 229-239.
Oei E, Kalb T, Beuria P, Allez M, Nakazawa A, Azuma M, Timony M, Stuart Z, Chen H, Sperber K (2004) Accessory cell function of airway epithelial cells. Am J Physiol Lung Cell Mol Physiol 287: L318331.

Pang L, Knox AJ (2001) Regulation of TNF-alpha-induced eotaxin release from cultured human airway smooth muscle cells by beta2agonists and corticosteroids. Faseb J 15: 261-269.

Paplinska M, Chazan R, Grubek-Jaworska H (2011) Effect of phoshpodiesterase 4 (PDE4) inhibibtors on eotaxin expression in humen bronchial epithelial cells. J Physiol Pharmacol 62: 303-311.

Rabe KF (2011) Update on roflumilast a phosphodiesterase 4 inhibitor for the treatment of chronic obstructive pulmonary disease. $\mathrm{Br} \mathrm{J}$ Pharmacol 163: 53-67.

Reddel RR, Ke Y, Gerwin BI, McMenamin MG, Lechner JF, Su RT, Brash DE, Park JB, Rhim JS, Harris CC (1988) Transformation of human bronchial epithelial cells by infection with SV40 or adenovirus-12 SV40 hybrid virus or transfection via strontium phosphate coprecipitation with a plasmid containing SV40 early region genes. Cancer Res 48: 1904-1909.

Rennard SI, Calverley PMA, Goehring UM, Bredenbröker D, Martinez FJ (2011) Reduction of exacerbations by the PDE4 inhibitor roflumilast--the importance of defining different subsets of patients with COPD. Respir Res 12: 18.

Rokudai A, Terui Y, Kuniyoshi R, Mishima Y, Mishima Y, Aizu-Yokota E, Sonoda Y, Kasahara T, Hatake K (2006) Differential regulation of eotaxin-1/CCL11 and eotaxin-3/CCL26 production by the TNF-alpha and IL-4 stimulated human lung fibroblast. Biol Pharm Bull 29: 1102-1109.

Sabatini F, Petecchia L, Boero S, Silvestri M, Klar J, Tenor H, Beume R, Hatzelmann A, Rossi GA (2010) A phosphodiesterase 4 inhibitor roflumilast $\mathrm{N}$-oxide inhibits human lung fibroblast functions in vitro. Pulm Pharmacol Ther 23: 283-291.

Shen J, Behrens C, Wistuba II, Feng L, Lee JJ, Hong WK, Lotan R (2006) Identification and validation of differences in protein levels in normal premalignant and malignant lung cells and tissues using high-throughput Western Array and immunohistochemistry. Cancer Res 66: 11194-11206.

Silva PM, Alves AC, Serra MF, Pires AL, Silva JP, Barreto EO, Cordeiro RS, Jose PJ, Teixeira MM, Lagente V et al. (2001) Modulation of eotaxin formation and eosinophil migration by selective inhibitors of phosphodiesterase type 4 isoenzyme. Br J Pharmacol 134: 283-294.

Stewart CE, Torr EE, Mohd Jamili NH, Bosquillon C, Sayers I (2012) Evaluation of differentiated human bronchial epithelial cell culture systems for asthma research. J Allergy (Cairo) 2012: 943982.

Suzuki T, Yamaya M, Sekizawa K, Yamada N, Nakayama K, Ishizuka S, Kamanaka M, Morimoto T, Numazaki Y, Sasaki H (2000) Effects of dexamethasone on rhinovirus infection in cultured human tracheal epithelial cells. Am J Physiol Lung Cell Mol Physiol 278: L560571.

Tralau-Stewart CJ, Williamson RA, Nials AT, Gascoigne M, Dawson J, Hart GJ, Angell ADR, Solanke YE, Lucas FS, Wiseman J et al. (2011) GSK256066 an exceptionally high-affinity and selective inhibitor of phosphodiesterase 4 suitable for administration by inhalation: in vitro kinetic and in vivo characterization. J Pharmacol Exp Ther 337: 145-154.

Wuyts WA, Vanaudenaerde BM, Dupont LJ, Demedts MG, Verleden GM (2003) Modulation by cAMP of IL-1beta-induced eotaxin and MCP-1 expression and release in human airway smooth muscle cells. Eur Respir J 22: 220-226. 
